\title{
ALTERAÇÕES HISTOLÓGICAS E COMPORTAMENTAIS PROVOCADAS PELA INOCULAÇÃO DE SUSPENSÃO BACTERIANA (Aeromonas hydrophila) EM JUVENIS DE JUNDIÁ (Rhamdia quelen) ${ }^{1}$
}

\author{
HISTOLOGYCAL AND BEHAVIORAL ALTERATIONS INDUCED BY THE INOCULATION \\ OF BACTERIAL SUSPENSION (Aeromonas hydrophila) IN \\ JUNDIÁ (Rhamdia quelen)
}

Cheila de Lima Boijink ${ }^{2}$ Deodoro Atlante Brandão ${ }^{3}$

RESUMO

Com objetivo de avaliar as alterações histológicas e comportamentais provocadas pela Aeromonas hydrophila em Rhamdia quelen, diferentes concentrações bacterianas $\left(3,6 \times 10^{7}\right.$ e 7,5 × $10^{6}$ UFC - Unidade Formadora de Colônia/ml de solução salina) foram inoculadas por via intramuscular. Para este estudo, foram utilizados 80 juvenis de jundiá com peso e comprimento de $16,55 \mathrm{~g}$ e 13,23cm, respectivamente. Esses peixes foram mantidos durante 10 dias, em caixas d'água de 250 litros, com condições iguais de temperatura, $\mathrm{pH}$, alcalinidade e dureza. Os jundiás foram observados diariamente e, os moribundos, submetidos a cortes histológicos. Constatou-se então que a Aeromonas hydrophila causa perda de equilíbrio, apatia e exoftalmia, assim como alterações histológicas na pele do tipo necrose, hemorragia e infiltrado inflamatório, atingindo tanto a camada da epiderme como da derme e musculatura.

Palavras-chave: ictiopatologia, A. hydrophila, jundiá

\section{SUMMARY}

The purpose of this study was to evaluate the histological and behavior alterations induced by the inoculation of different concentrations of Aeromonas hydrophila in jundiás. Eighty (80) animals were used in this study, with $16.55 \mathrm{~g}$ of weight and $13.23 \mathrm{~cm}$ of length. Different bacterial concentrations $(3.6 x$ $10^{7}$ and $7.5 \times 10^{6}$ UFC - Unity Formation of Colony/ml of saline solution) were inoculated intramuscularly. The animals were kept for 10 days in amianthus aquarium (250 liters) with similar conditions of temperature, $\mathrm{pH}$, alkalinity and hardness. The jundiás were observed daily and the dying ones were used for histological cuts. It was verified that the Aeromonas hydrophila caused balance loss, apathy, exophthalmia and histological alterations like necrosis, hemorrhage and inflammatory infiltrated, reaching the epidermis layer as well as the derme and musculature.

Key words: ictiopathology, A. hydrophila, jundiá

\section{INTRODUÇÃO}

As bactérias que fazem parte da microbiota aquática são consideradas como patogênicas oportunistas para peixes, visto que só se manifestam, provocando infecções, quando os peixes se encontram em condições ambientais desfavoráveis (BARJA \& ESTEVES, 1988). Estes organismos podem, quando ingeridos ou em contato com lesões da epiderme, causar doenças, tanto em animais como em humanos (USFDA, 1999).

Segundo ROBERTS (1981), a pele é a primeira barreira de proteção dos peixes frente ao meio externo. Permite uma normal função fisiológica interna, bem como proteção nos processos de enfermidades. A epiderme dos peixes apresenta múltiplas propriedades, dependentes da produção de secreções pela camada superficial que apresenta importante função de lubrificação e proteção, impedindo a invasão e proliferação de microorganismos patógenos, permitindo assim que a mesma permaneça hidratada e com viscoelasticidade, proporcionando uma adaptação para a peculiar vida dos peixes

${ }^{1}$ Projeto financiado pelo CAPES.

${ }^{2}$ Biólogo, aluno do curso de mestrado em Zootecnia, Centro de Ciências Rurais (CCR), Universidade Federal de Santa Maria (UFSM).

${ }^{3}$ Biólogo, PhD, Professor Titular, Departamento de Zootecnia, CCR, UFSM, 97105-900, Santa Maria, RS. E-mail: dabrandao@pro.viars.com.br. Autor para correspondência. 
(MITTAL, 1997). Muitas vezes, em cultivo intensivo, toda essa proteção não é suficiente para impedir um surto epizoótico nos peixes. Em alguns casos, não há ocorrência de mortalidade, mas a sobrevivência futura, poderá ficar comprometida quando houver novas agressões (KINKELIN et al., 1985).

Além das perdas econômicas que as bactérias podem ocasionar, pela mortalidade que provocam, geralmente produzem lesões cutâneas, retardam o crescimento e o ganho de peso e impedem o seu consumo. Os altos investimentos em tratamentos terapêuticos também representam perigo para as populações naturais de peixes e uma ameaça sanitária direta ou indireta para a saúde humana.

Conforme AUSTIN \& AUSTIN (1993), na atualidade são descritos como microorganismos patógenos para peixes uma grande variedade de grupos bacterianos, no entanto, somente um pequeno número causa perdas econômicas importantes nos cultivos intensivos de todo mundo. Dentre as bactérias consideradas patogênicas aos peixes está a Aeromonas hydrophila, a qual foi isolada e identificada de lesões externas e do rim por SHAMA et al. (2000) em jundiá (R. quelen) criados em tanques em Santa Maria (RS).

ROBERTS (1981) cita como patologia clínica da $\boldsymbol{A}$. hydrophila: escurecimento da pele, ascite, assim como hemorragias externas e irregulares na superfície do corpo e na base das nadadeiras. $\mathrm{Na}$ necropsia, os órgãos internos se encontram congestionados e as vísceras cobertas de hemorragias; Além disso, o rim e o baço se apresentam tumefados, com um líquido semifluído; Também há graves lesões na pele, edemas na derme, ulceração na epiderme. $\mathrm{O}$ autor também ressalta necroses hemorrágicas podem alcançar o músculo.

Tendo em vista a expansão da piscicultura, a aceitação comercial do jundiá e o alto risco de infecção por bactérias patogênicas nestes peixes, foi realizado o presente trabalho que tem por objetivo: avaliar as alterações histológicas e comportamentais causadas pela inoculação intramuscular de suspensões de Aeromonas hydrophila em juvenis de jundiá (Rhamdia quelen).

\section{MATERIAL E MÉTODOS}

O presente trabalho foi desenvolvido no Laboratório de Bacteriologia do Departamento de Medicina Veterinária Preventiva e no Laboratório de Ictiopatologia do Departamento de Zootecnia da Universidade Federal de Santa Maria (UFSM) e no Laboratório de Histologia Animal do Departamento de Patologia e Clínica Veterinária da Universidade Federal do Rio Grande do Sul. Para inoculação, foram utilizados 60 jundiás (Rhamdia quelen), com peso médio de $16,55 \mathrm{~g}$ e comprimento de $13,23 \mathrm{~cm}$. Vinte (20) jundiás, mantidos como testemunhas, não foram inoculados. Os animais inoculados foram divididos em 6 grupos de 10 peixes e mantidos durante 10 dias em caixas d'água de cimento amianto com capacidade de 250 litros e abastecidas com água de poço artesiano. Todas as caixas foram submetidas a condições iguais de temperatura $\left(25^{\circ} \mathrm{C}\right)$, oxigênio $(7,9 \mathrm{mg} / \mathrm{l})$, amônia não ionizada $(0,006 \mathrm{mg} / \mathrm{l}), \mathrm{pH}(7,1)$, alcalinidade total $(36 \mathrm{mg} / \mathrm{l}$ $\left.\mathrm{CaCO}_{3}\right)$ e dureza total $\left(24 \mathrm{mg} / 1 \mathrm{CaCO}_{3}\right)$. Para alimentação dos juvenis foi administrada uma ração comercial, contendo $36 \%$ de proteína bruta, na proporção de $3 \%$ da biomassa, uma vez ao dia.

O inóculo bacteriano foi preparado através da cultura de Aeromonas hydrophila em ágar sangue, sendo as colônias suspensas em solução salina estéril. A turvação foi ajustada segundo a escala $0,5\left(3,6\right.$ x $\left.10^{7} \mathrm{UFC} / \mathrm{ml}\right)$ e $0,25(7,5 \mathrm{x}$ $10^{6} \mathrm{UFC} / \mathrm{ml}$ ) de MacFarland (VANDEPITTE $\boldsymbol{e t}$ al. 1993). Os jundiás foram inoculados com as duas concentrações de $\boldsymbol{A}$. hydrophila $\left(3,6\right.$ x $10^{7}$ e 7,5 x $10^{6} \mathrm{UFC} / \mathrm{ml}$ de solução salina), sendo um grupo controle, no qual os animais receberam apenas solução salina estéril. Cada jundiá foi inoculado com $1 \mathrm{ml}$ da respectiva suspensão, por via intramuscular, na região dorso-lateral direita entre a nadadeira dorsal e a linha lateral. Antes da inoculação, os animais foram pesados e medidos.

As caixas foram limpas e observadas diariamente. Nesta oportunidade, foram verificadas alterações comportamentais, sinais clínicos externos, bem como a morbidade e mortalidade ocasionada pela Aeromonas hydrophila em cada grupo de jundiás inoculados.

Os animais que se apresentavam moribundos no momento da limpeza diária das caixas, foram separados para observação das alterações histológicas. Os tecidos foram fixados em solução de formalina tamponada neutra à $10 \%$, incluídos em parafina, cortados longitudinal e transversalmente com navalha descartável com 2 a $5 \mu \mathrm{m}$ de espessura e corados pela hematoxilina e eosina (CONROY \& HERMAN, 1970). A seguir, foi feita a coloração de Gram em tecido "BROWN - HOPPS GRAM STAIN", modificada por AFIP (PROPHET $\boldsymbol{e}$ t al., 1992), e essas preparações foram observadas ao microscópio de luz comum (NOGA, 1996).

\section{RESULTADOS E DISCUSSÃO}

Ao final dos 10 dias de experimento os peixes inoculados com $\boldsymbol{A}$. hydrophila na concentração de $10^{7}$ sofreram $100 \%$ de mortalidade 
e nos inoculados com $10^{6}$ foram verificados $25 \%$ de mortalidade. Foi demonstrado uma diferença altamente significativa entre os tratamentos com relação à sobrevivência pelo teste $\chi^{2}(\mathrm{P}<0,01)$. Trabalhos que podem servir como parâmetros para este estudo no que diz respeito à sobrevivência são os que testaram a $\mathrm{DL}_{50}$ da $\boldsymbol{A}$. hydrophila em algumas espécies de peixes como SANTOS et al. (1991). Esses autores, através de inoculações intraperitoniais com doses de $10^{2}$ a $10^{8}$ células, testaram a virulência de algumas cepas de $\boldsymbol{A}$. hydrophila para peixes, ou seja, o número de células viáveis necessárias para matar $50 \%$ dos peixes inoculados, durante 7 dias $\left(\mathrm{DL}_{50}\right)$. Com isso, observaram que a quantidade aproximada para Salmo trutta foi de $2 \times 10^{5}$ células $/ \mathrm{ml}$, Anguilla japonica $>10^{8}$, Plecoglossus altivelis 8,6 X $10^{4}$, Leponis macrochirus $>10^{8}$, Oncorhynchus mykiss dependendo das cepas de bactérias variou de 3,2 x $10^{4} \mathrm{a}>10^{8}$. Este trabalho com $\mathrm{DL}_{50}$ pode mostrar a variação da virulência característica da bactéria, que causou letalidade na concentração $10^{7}$ para jundiá (R. quelen). Essa mortalidade, segundo THUNE $\boldsymbol{e t}$ al. (1982), depende da virulência da bactéria o que está associada à produção de enzimas próprias bem como da atividade citotóxica de uma cepa de bactéria que varia de acordo com a célula utilizada RODRÍGUEZ et al. (1992a).

Os sinais clínicos, apresentado pelos peixes, após a inoculação, com bactérias de ambas as suspensões, foram comportamentais. Os peixes ficaram parados no fundo da caixa; alguns vinham à superfície mas logo desciam, parecendo perder o equilíbrio. A maior parte do tempo, eles permaneciam parados no fundo. Quando se alimentavam, pegavam a ração já no fundo. Este mesmo distúrbio comportamental foi observado por NIETO et al. (1991) e RODRÍGUEZ et al. (1992b).

Os juvenis também apresentavam ulcerações com bordas hemorrágicas, deixando, a maioria das vezes, a musculatura exposta e a região lateral dorsal direita com pigmentação anormal, necrose das nadadeiras, lesões no poro genital, no ânus e parte externa da mandíbula, brânquias pálidas e flácidas. Manchas hemorrágicas internas cobrindo toda a região dorsal da cabeça também foram observadas. LLOBRERA \& GACUTAN (1987) também observaram úlceras necróticas abertas sobre o corpo, a mandíbula e na região do pedúnculo caudal em Ophicephalus striatus, Clarias batrachus, Carassius sp. e Glossogobius giurus, contaminados com Aeromonas hydrophila.

Já os jundiás inoculados com solução salina (controle) não apresentaram nenhum sinal clínico ou alterações no comportamento.
As alterações histológicas observadas com maior freqüência nas amostras da pele (epiderme, derme) e musculatura foram: necrose, hemorragia e infiltrados inflamatórios, sendo que o agravamento destas foi maior no decorrer dos dias de coleta dos animais. Também foi observada congestão na musculatura e edemas na derme. As lesões na pele, edema da derme e hiperemia do extrato reticular, conduziram a uma esponjosidade e ulceração da epiderme, seguida de uma extensa necrose hemorrágica que, na maioria das amostras, alcançou o músculo. Nos infiltrados inflamatórios observados, foi possível identificar células de defesa como: macrófagos, linfócitos, neutrófilos e trombócitos. Através da coloração de Gram dos tecido, ficou também bem visível a presença de bactéria.

Segundo McDANIEL (1979), a doença por A. hydrophila pode ocorrer na forma superaguda, aguda, subaguda e crônica. As formas superaguda e aguda são caracterizadas pela alta mortalidade e lesões hemorrágicas internas pronunciadas. As formas subaguda e crônica ocorrem com hemorragias nas brânquias, aberturas naturais, órgãos internos e presença de fluído sanguinolento nas cavidades do corpo; sendo também evidentes abscessos e úlceras externas. Quanto aos peixes portadores, o autor os descreve sem manifestação clínica aparente (assintomáticos). Segundo as descrições de McDANIEL, pode-se dizer que nesta pesquisa, induziram-se os jundiás a uma infecção subaguda ou crônica.

As alterações comportamentais e histológicas na pele observadas neste estudo apresentaram algumas variações em relação a outros trabalhos. PLUMB (1994), trabalhando com A. hydrophila, encontrou lesões epidérmicas esbranquiçadas. SCHLOTFELDT \& ALDERMAM (1995) também observaram que a infecção por $\boldsymbol{A}$. hydrophila pode apresentar hemorragia nas brânquias e outros sinais clínicos como lesões ulcerativas na pele e músculo, necrose das nadadeiras e região caudal, o que também pode ser visto neste trabalho.

Conforme SHAMA et al. (2000), o jundiá pode ser portador de bactérias descritas como patogênicas, tais como $\boldsymbol{P}$. shigelloides, Aeromonas sp., Flavobacterium sp., Pseudomonas sp., Staphylococcus sp., Edwardsiella tarda, Yersinia ruckeri, Vibrio sp., Micrococcus sp., Acinetobacter sp. e Pasteurella sp. Já BOIJINK et al. (1999) ao inocularem Plesiomonas shigelloides por via intramuscular em jundiás mantidos em caixas contendo Aeromonas hydrophila, verificaram que a associação das duas bactérias induziu lesões patológicas nestes animais. Nesse mesmo trabalho, no qual também foram utilizados jundiás, foi verificado que, quando há uma infecção por grande 
quantidade de células de Aeromonas hydrophila, também ocorrem lesões ulcerativas com significativas alterações histológicas e comportamentais em jundiá.

\section{CONCLUSÕES}

A bactéria Aeromonas hydrophila causa alterações histológicas como necrose, hemorragia e infiltrados inflamatórios tanto na pele, como no tecido múscular do jundiá (Rhamdia quelen) tendo sido observadas, também, mudanças comportamentais como perda do equilíbrio e, em sua grande parte, a permanência dos peixes no fundo das caixas.

\section{REFERÊNCIA BIBLIOGRÁFICA}

AUSTIN, B., AUSTIN, D.A. "Fish pathogens diseases in farmed and wild". Chichester, UK : Ellis Horwood, 1993. $123 \mathrm{p}$.

BARJA, J.L. ESTEVES, A.T. Patologia acuicultura. Espanha: Caicyt, 1988. 550p.

BOIJINK, C.L., COSTA, M.M., VARGAS, A.C. et al. Efeito da inoculação de suspensão bacteriana de Plesiomonas shigelloides e da presença de Aeromonas hydrophila na água de cultivo de jundiá (Rhamdia quelen). In: REUNIÃO ANUAL DA SOCIEDADE BRASILEIRA DE ZOOTECNIA, 36, 1999, Porto Alegre, RS. Anais... Porto Alegre : Universidade Federal do Rio Grande do Sul, 1999. p.318.

CONROY, D.A., HERMAN, R.L. Textook of fish diseases. New Jersey : TFH, 1970. 302p.

KINKELIN, P., MICHEL, C.H., GHITTINO, P. Tratado de las enfermedades de los peces. Zaragoza : Acribia, 1985. 353p.

LLOBRERA, A.T., GACUTAN, R.Q. Aeromonas hydrophila associated with ulcerative disease epizootic in Laguna de Bay, Philippines. Aquaculture, v.7, p.273-278, 1987.

McDANIEL, D. American Fisheries Society: Fish Health Section. Washington : Copyright, 1979. Procedures for the detection and identification of certain fish pathogens: $118 \mathrm{p}$.

MITTAL, A.K. Fish skin glands e their secretions. In: INTERNATIONAL SYMPOSIUM. BIOLOGY OF TROPICAL FISHES, 1997. Manaus, Amazonas, Brasil. Anais... Manaus : Universidade do Amazonas, 1997. p.5.

NIETO, T.P., ELLIS, A.E. Heterogenecity of extracellular proteases produced by different isolates of Aeromonas hydrophila and Aeromonas sobria pathogenic for fish. Journal of Fish Diseases. v.14, p.229-235, 1991.

NOGA, E.J. Fish diseases. Baltimore, USA : Mosbi, 1996. 125p.

PLUMB, J.A. Health maintenance of cultured fishs: principal microbial diseases. USA: CRC, 1994. 254p.

PROPHET, E.B., MILLS, B., ARRINGTON, J.B., et al. Laboratory methods in histotechnology. Washington: American registry of Pathology, 1992. p.221-222.

ROBERTS, R.J. Patologia de los peces. Madrid : Mundi-Prensa., 1981. 336p

RODRÍGUEZ, L.A., ELLIS, A.E., NIETO, T.P. Purification and characterisation of na extracellular metalloprotease, serineprotease and haemolysin of Aeromonas hydrophila strain $\mathrm{B}_{32}$ : all are lethal for fish. Microbial Pathogenesis, v.14, p.10$18,1992 \mathrm{a}$.

RODRÍGUEZ, L.A., ELLIS, A.E., NIETO, T.P. Effects of the acetylcholinesterase toxina of Aeromonas hydrophila on the central nervous system of fish. Microbial Pathogenesis, v.14, p.19-24, 1992b.

SANTOS, Y., BANDÍN, I., NIETO, T.P., et al. Cell-surfaceassociated properties of fish pathogenic bacteria. Journal of Aquatic Animal Health, v.3, p.297-301, 1991.

SCHLOTFELDT, H.J., ALDERMAN, D.J. A practical guide for the fresh water fish farmer. Bulletin European Association of Fish Pathologists, Weymouth - UK, v.15, n.4, p.134-157, 1995 .

SHAMA, S., BRANDÃO, D.A., VARGAS, A.C. $\boldsymbol{e} \boldsymbol{t} \boldsymbol{a l}$. Ocorrência de bactérias com potencial patogênico em jundiás (Rhamdia quelen) cultivados em sistema semi-intensivo. Ciência Rural, v.30, n.2, p.293-298, 2000.

THUNE, R.L., GRAHAM, T.E., RIDDLE, L.M., $\boldsymbol{e} \boldsymbol{t} \boldsymbol{a l}$. Extracellular products and endotoxin from Aeromonas hydrophila: Effects on Age-0 channel catfish. Transactions of the American Fisheries Society, v.111, n.3, p.404-408, 1982 .

THUNE, R.L., STANLEY, L.A., COOPER, R.K. Pathogenesis of gran-negative bacterial infections in warm water fish. Annual Rev of Fish Diseases, v.9, p.37-68, 1993.

USFDA (FOOD \& DRUG ADMINISTRATION). Center for Food Safety \& Applied Nutrrition (CFSAN). Foodborne pathogenic microorganisms and natural toxins handbook. p.1-3, 1999. (INTERNET: http://um.cfsan.fda.gov).

VANDEPITTE, J., ENGBAEK, K., PIOT, P., HEUCK, C.C. Métodos básicos de laboratório em bacteriologia clínica. Genebra : Organização Mundial de Saúde, 1993. 122p. 